\title{
CONSIDERACIONES JURÍDICAS EN TORNO A LA REDUCCIÓN DE LA EDAD PUNIBLE EN HONDURAS
}

\section{Abogada Alba Alonzo de Quesada ${ }^{1}$}

$\mathrm{H}$ onduras es un país con 112,492 kilómetros cuadrados de territorio, con una población de 8,303,416 de habitantes, de los cuales 2,472,798 están en edad de 5 a 18 años; de ellos asisten a la escuela 1,318,674 en el rango de 7 a 18 años y no asisten a la escuela ni trabajan en el rango de 12 a 18 años un total de 221,308; de estos, 518 están privados de libertad por infracciones a la Ley, los cuales son penalmente no imputables por su edad, cuando cometen infracciones y están sujetos a la normativa especial contenida en el Código de la Niñez y de la Adolescencia (Fondo de la Población, Naciones Unidas, 2017)

Tomando como referente los datos estadísticos anteriores, podríamos aseverar que el límite de edad es un concepto categórico, y se hace efectivo desde el momento en que un menor incursiona en alguna tipología tipificada como delito en el Código Penal y Procesal penal en Honduras.

Así también, es importante mencionar que al momento de deducirle responsabilidad penal a un menor infractor, ese límite de edad biológica es verificado por el Señor y/o la Señora Juez, por ser la autoridad judicial responsable de analizar el estudio o dictamen social, educativo y psicológico del menor previo a dictar la sentencia correspondiente.

El límite de la edad Punible aparece contemplado por primera vez en el Código Penal de 1906, donde se exime de toda responsabilidad al menor de 10 años y al menor de 15, siempre y cuando no haya obrado con malicia o discernimiento (Congreso Nacional, República de Honduras, 1906).

Podríamos afirmar entonces que ése código, constituye la panacea que da origen a la reglamentación en cuanto a la inimputabilidad de un menor infractor, permitiendo la imposición de sanciones independientes al sistema de sanciones penales exclusivas para adultos.

En 1957 la legislación para el tratamiento de menores y/o adolescentes infractores, se interna en la doctrina de la SITUACIÓN IRREGULAR, es decir, que según la edad descrita en la Constitución de la República, esta obligaba al Estado a velar por la infancia creando dependencias gubernamentales e instalaciones adecuadas y en caso de ser fundadas por iniciativa privadas se les consideraba de orden público por ser de asistencia social.

En ese orden de ideas, los menores delincuentes y pre-delincuentes estaban sometidos a una legislación especial de vigilancia, rehabilitación y protección, no permitiendo el ingreso de un menor de 18 años a una cárcel o presidio, tal lo dispone la Ley de Jurisdicción de menores de 1969, que se caracterizaba por considerar al menor abandonado como un pre-delincuente, y darle a la vez compasión y represión a discrecionalidad del Juez (Congreso Nacional, República de Honduras, 1969). Las Constituciones de 1965 y 1982 reiteran estas disposiciones.

Fecha de Recepción: 19 de octubre del 2017

Fecha de Aceptación: 21 de noviembre del 2017

1 Primera mujer graduada de Abogada, de la Universidad Nacional Autónoma de Honduras UNAH.

E-mail: maribel03hn@yahoo.com 
Por su parte, en 1989 las Naciones Unidas aprueban la Convención Internacional de los Derechos del Niño basada en la doctrina de la PROTECCIÓN INTEGRAL de la infancia acompañada de los siguientes instrumentos jurídicos aprobados con anterioridad a ella:

1. Las Reglas Mínimas de Beijing para la administración de Justicia Juvenil

2. Las Reglas Mínimas de Naciones Unidas para los Jóvenes Privados de Libertad

3. Las Reglas Mínimas de las Naciones Unidas sobre las medidas no privativas de la libertad, Reglas de Tokio

4. Las Directrices de las Naciones Unidas sobre la administración de justicia llamadas directrices de READ y además, de varios Protocolos Facultativos sobre la venta de niños, la prostitución infantil, la utilización de niños en la pornografía y la participación de niños en conflictos armados, entre otros.

Las Naciones Unidas, a fin de dar fiel cumplimiento a dicha Convención, ha creado en la actualidad, El Comité de Derechos del Niño, el cual tiene entre una de sus funciones, obligar a los estados miembros a rendir un informe de cumplimiento relacionado con la protección infantil con el objetivo fundamental de que sus disposiciones no queden en letra muerta.

La Convención de los Derechos del Niño es un instrumento jurídico creado para garantizar no sólo aquellas condiciones jurídicas y políticas inherentes a un niño, sino que también aquellas garantías sociales, culturales, y sobre todo para tratar al niño como un sujeto de derecho y no como un objeto (UNICEF, 1989).

Honduras suscribe dicha Convención y la ratifica en mayo 1990, e inicia la armonización de la legislación de menores y sus políticas sociales acordes con la misma, así concuerda con el Código de la Niñez y la Adolescencia con las nuevas especialidades como las defensorías de la Niñez en las Alcaldías Municipales, las Consejerías Familiares en el Ministerio de Salud, la Oficina Defensora de los niños en el Ministerio Público, entre otras, pero sobre todo le da al Instituto de la Niñez y la Familia, antes Junta de Bienestar Social el mandato con la responsabilidad de formular y ejecutar las políticas del Estado en las áreas de la niñez, la adolescencia y la familia, dicho Instituto actualmente llamado Dirección Nacional de la Infancia, Adolescencia y Familia (DINAF).

A pesar del trabajo realizado, podría señalarse que existen grandes limitantes en cuanto una protección integral del niño y del adolescente, mismas que están vinculadas casi siempre a la pobreza y a una anticultura de violencia que hacen casi invisible los esfuerzos para superarlos.

A razón de ello, El Código de la Niñez y la adolescencia de Honduras, establece las medidas a imponer a un menor infractor, que van desde orientación y apoyo socio familiar, hasta el internamiento en uno de los Centros Pedagógicos dependiendo la gravedad de la infracción, las circunstancias que la han rodeado, así como, con las necesidades del menor y de la sociedad en general (Congreso Nacional, 1996)

De acuerdo con la estadísticas, en el año 2016 los Juzgados de menores dictaron 2,398 sentencias condenatorias, de las cuales unas 500 con medidas sustitutivas para los niños infractores, a quienes el DINAF se encarga de establecer medidas para su rehabilitación, como hacerlos regresar al Centro Educativo donde estudiaba, realizar trabajos comunitarios, recibir talleres, entre otras (Asociación Sociedad, 2016). 
En base a las estadísticas presentadas por la Asociación para una sociedad más justa, gran parte de los delitos cometidos en nuestro país son cometidos por menores de edad, siendo los delitos más comunes en que estos incurren los siguientes: a) extorsión, b) tenencia y portación de armas prohibidas c) robo d) narcotráfico y; e) sicariato. Con relación a éste último y en la mayoría de los casos, los menores son utilizados por personas adultas. Es por ello, que se ha visto con preocupación el incremento de las sentencias privativas de la libertad, no obstante el Código establece que dicha sanción es excepcional, es decir, que solo en último extremo se puede imponer.

Existen en el país cinco (5) Centros institucionales creados para hacer efectivo el cumplimiento de las sanciones pronunciadas por los órganos estatales a través de la Corte Suprema de Justicia, el gobierno les denomina "Centros Pedagógicos" estos han sido diseñados a fin de rehabilitar y reinsertar a un menor infractor a la sociedad. Cabe señalar que aun con el propósito antes mencionado, dichos centros no han sido del todo seguros puesto que en lugar de reinsertarlos, se han convertido en Centros de violencia, donde impera la incertidumbre, el temor, las fugas constantes y por qué no decirlo, la muerte.

Ante la alta incidencia de crímenes y ola de violencia con la participación de menores en Honduras, el Gobierno de la República propuso como tema de discusión la disminución y/o reducción de la edad punible a los menores infractores que oscilaran entre los 16 a 18 años, así como también proponía el aumento de las penas con el objetivo de proteger a la sociedad de los delincuentes y brindarles mayor seguridad.

Actualmente los cambios relacionados a la mayoría de la edad penal, no nos hace ningún avance en cuanto a la seguridad pública porque la violencia está asociada, no solo a la desatención del Estado, a las políticas sociales, sino que también a la falta de valores para la solidaridad de la población con respecto a los derechos de la niñez y la adolescencia.

Dichas medidas deberían de ser acompañadas por una Política Pública encaminada a enfrentar la problemática de la niñez y la adolescencia desde sus orígenes: la familia, la escuela y el vecindario, que viven situaciones que generalmente son producto de la pobreza, la exclusión social, la ruptura social y la desigualdad.

Para el caso, la familia es el núcleo o base de la sociedad, es la formadora de los hijos, es la que inculca los valores que se necesitan en la vida, morales, sociales, intelectuales, entro otros y si esta no es fortalecida, traerá consigo graves y futuros problemas que el estado deberá enfrentar.

Actualmente la sociedad a nivel mundial, enfrenta el grave problema de la desintegración familiar que como es sabido, existe una ausencia parcial, temporal o total de uno de los progenitores; lo que deviene en represiones de orden psicológico, económico, educativo y cultural especialmente en los hijos, y que se traduce finalmente en conductas juveniles problemáticas.

De conformidad a la Constitución de la República, la educación básica es obligatoria y gratuita, por lo que no se puede tener ningún pretexto para no asistir o abandonarla por falta de recursos económicos, pero la situación actual del país por mucho esfuerzo que realice, no permite dar fiel cumplimiento a este mandato. 
La Escuela debe ser el centro de atención del vecindario, en ella el menor debe sentirse cómodo, y el aprendizaje para su formación no solo tienen que ser intelectual, sino que físico y moral, por lo que ésta debe tener además de sus aulas de clase, su patio, área recreativa y una parcela para que el alumno aprenda a cultivar y desarrollar un aprecio por la agricultura, la horticultura y el ornato.

Además, la escuela debe estar atenta a enseñar artes y deportes; sus docentes deben evitar por todos los medios la deserción escolar, si esta sucede por causas ajenas a las mismas, el maestro debe buscar la forma de reingresar al menor, ya sea buscando la ayuda de los padres y si estos no existen, buscar el apoyo de las autoridades superiores.

El Estado debe estar atento a evitar este tipo de situaciones, se debe buscar atraer al menor y al vecindario a la escuela como foco principal de actividades educativas, culturales, sociales y deportivas.

En el vecindario se deben aprovechar las estructuras llamadas "recreo vías" para que no sean solo espacios de esparcimiento, sino que también se puedan recibir enseñanzas pedagógicas y culturales, para mejorar la calidad de las relaciones familiares y de la comunidad.

Para realizar un cambio real y concreto es necesario hacer efectiva la aplicación de los derechos humanos, el Código de Familia, la Convención de los Derechos del Niño y otras leyes relativas; asimismo, implementar programas que propicien la ayuda mutua entre las personas a efecto de fortalecer la convivencia y solidaridad entre los miembros de comunidad.

En cuanto al sistema escolar, se torna necesario capacitar a los docentes para que puedan detectar las señales de violencia en los menores de edad y proceder de conformidad a lo contemplado en los diferentes compendios jurídicos dedicados a proteger al infante.

Otra de las situaciones de riesgo en que incurren los menores en Honduras, es el niño obligado a trabajar en la calle, el cual se expone a ser víctima no solo de un ataque físico si no que ser utilizado por adultos para actividades delictivas.

Sin duda alguna, para reducir los índices de niños viviendo en la calle y en situación de riesgo, se deben desarrollar programas relacionados con el ordenamiento poblacional, por ejemplo, construir una base de datos con un historial general, es decir, datos que permitan identificarlos y ubicarlos en su grupo familiar, en su vecindario y escuela. 


\section{CONCLUSIONES}

- Honduras es un país suscriptor de tratados internacionales y por ende debe buscar no transmitir una justicia inquisitiva en la que se ataque al fenómeno de la delincuencia juvenil en su última etapa, sino por el contrario, debe establecer un periodo prudencial a fin de fortalecer los sistemas de prevención que eviten que el Estado utilice la privación de libertad como último recurso.

- El menor infractor no debe ser visto como un sujeto afecto a reintegrarse a la sociedad, por el contrario, deben aplicarse políticas claras de reinserción, con el fin de realizar un proceso óptimo y completo en el cual sea suprimida la conducta ilícita y transformar al menor en materia activa para la construcción de un mejor país.

- Honduras posee un sistema acusatorio en materia de niñez, no está preparado de manera idónea para enfrentar la problemática actual como lo es la reducción de la edad punible ya que las políticas de Estado en lugar de enfocarse en la prevención, se enfatizan en darle persecución al menor infractor, generando así una inevitable comisión del ilícito.

- Previo a considerar la reducción de la edad punible en el país y de aumentar las penas para los $m$ enores y adolescentes infractores, debería realizarse un estudio profundo de los temas antes mencionados, a fin de tomar medidas de prevención y no de coerción. 


\section{BIBLIOGRAFÍA}

- Asociación Sociedad, mas justa(2016). Estudio situacional sobre las condiciones de privación de libertad de la niñez infractora por la ley penal. Tegucigalpa: Editores.

- Auto Acordado (1987) Corte Suprema de Justicia para Juzgado de Menores, Familia y Junta de Bienestar Social. Tegucigalpa.

- Congreso Nacional, Honduras (1980). Constitución de la República de Honduras, Tegucigalpa: Graficentro Editores.

- Congreso Nacional, Honduras (1906). Código Penal de Honduras. Tegucigalpa: Graficentro Editores.

- Congreso Nacional, R. d. (1996). Código de la Niñez y de la Adolescencia. Tegucigalpa: Graficentro Editores.

- Congreso Nacional, República de Honduras. (22 de Enero de 1906). Codigo Penal de Honduras. Tegucigalpa, Honduras: Guaymuras.

- Congreso Nacional, República de Honduras. (1969). Ley de Jurisdicción de 1969. Tegucigalpa: Graficentro Editores.

- Díaz Claudia (1998) Delincuencia Juvenil dentro del contexto de la Doctrina de la Protección Integral. Argentina.

- Fondo de la Población, Naciones Unidas. (Octubre de 20 de 2017). En Honduras hay más de 600 mil Jóvenes Ninis. La Prensa, pág. 21.

- García Emilio (1994 ) Derechos de la Infancia, adolescencia en América Latina.

- Ley de Jurisdicción de Menores (1969-1978), Congreso Nacional, Tegucigalpa, Guaymuras.

- Ley del Instituto Hondureño de la Niñez y la Familia (1998) Congreso Nacional de Honduras. Tegucigalpa.

- Save The Children (1998) Las Pandillas Juveniles: Causa o Efecto de la Violencia. Save the Children Honduras, 1998.

- UNICEF. (1989). Convención sobre los Derechos del Niño. Somalia: Nuevo Siglo.

- Unicef (2013) Justicia Penal Juvenil: Situación y Perspectivas en América Latina y El Caribe. 